\title{
Proposta de uma metodologia para mensurar o nível de dependência do tomador de decisão em relação às fontes de informações: o caso dos pequenos varejos da região do Barro Preto em Belo Horizonte
}

Paulo Henrique de Oliveira

\begin{abstract}
Administrador e Mestre em Engenharia da Produção pela UFMG; Professor de Nível Superior em Instituições de Ensino Superior em nível de graduação e pós-graduação nos cursos de Administração e Sistemas de Informação.
\end{abstract}

Apresenta uma metodologia para avaliar o nível de dependência do decisor em relação à determinada fonte de informação utilizada na tomada de decisão estratégica. Para tanto, utilizou-se uma pesquisa realizada pelo autor com nove lojistas localizados na região do Barro Preto em Belo Horizonte. Como resultado constatou-se que a metodologia pode ajudar o decisor a melhorar a eficácia do seu comportamento informacional, na medida em que demonstra o quanto uma fonte de informação é relevante para a sua tomada de decisão.

Palavras-chave: Fontes de Informação; Tomada de Decisão; Varejo; Empresas de Pequeno Porte.

\section{Proposal of a methodology to measure the level of dependence of the Decision Maker on Sources of Information: the case of small retailers in the region of Barro Preto in Belo Horizonte}

The article presents a methodology for assessing the level of dependence of the decision maker regarding a particular source of information used in strategic decision making. For that, a survey with nine merchants from Barro Preto region in Belo Horizonte was conducted by the author. It was found that the methodology can help the 
decision maker to improve the efficiency of the informational behavior as it demonstrates the extent to which a source of information is relevant for decision making.

Key words: Sources of Information. Decision Making. Retail. Small Enterprises.

Recebido em 25.06.2008 Aceito em 12.03.2009

\section{Introdução}

O aumento da complexidade e dinamicidade do ambiente de negócios tem delineado cenários cada vez mais incertos, voláteis e turbulentos para os responsáveis pela tomada de decisão estratégica (D 'AVENI, 1995; HITT et al, 2003). Vive-se numa era de incertezas, onde a capacidade de sobrevivência e crescimento das organizações, nos mercados em que atuam ao longo do tempo, vai depender, dentre outras coisas, das suas capacidades em se ajustarem rapidamente e eficazmente às mudanças impostas pelos seus ambientes em constante evolução. Assim, torna-se necessário que as organizações mantenham sistemas de monitoramento contínuo dos seus ambientes de negócios, identificando e selecionando as fontes de informações capazes de thes fornecer informações rápidas, precisas e confiáveis sobre fatos, eventos, relacionamentos e tendências que acontecem em seus ambientes e úteis para uma tomada de decisão cada vez mais eficiente e eficaz (SIMON, 1965; AGUILAR, 1967; DRUCKER, 1995).

Neste sentido, percebe-se que o aumento da incerteza e da volatilidade do ambiente de negócios tem colocado à prova a capacidade de sobrevivência e de crescimento das organizações nos mercados em que atuam ao longo do tempo, independentemente da sua forma legal, porte, nacionalidade ou setor de atividade. Reflexo de uma economia cada vez mais globalizada e dos avanços tecnológicos, o acirramento da competição tem reduzido as margens de erro dos decisores estratégicos e demandado posturas mais pró-ativas e comportamentos informacionais mais condizentes com as novas realidades competitivas, pautadas na rapidez, flexibilidade e constante capacidade de inovação e adaptação às mudanças ambientais, em que se busca evitar e/ou neutralizar as ameaças existentes, além de buscar e promover novas oportunidades de negócios.

E é neste contexto, em profunda transformação, que o presente artigo propõe uma metodologia para mensurar o nível de dependência dos decisores estratégicos em relação às fontes de informações disponíveis e utilizadas por eles em seus processos decisórios. Para a consecução desse objetivo central, escalas do tipo Likert foram utilizadas para mensurar a freqüência de uso e a importância percebida pelos decisores em relação às 
fontes de informações utilizadas por eles na consecução de suas atividades decisórias. No que tange à classificação das fontes de informações, foi utilizada a pesquisa realizada por Auster e Choo (1993) entre os gerentes canadenses. Assim, quatro grupos de fontes foram adaptados dos estudos deste autor: fontes pessoais internas; fontes pessoais externas; fontes impessoais internas e fontes impessoais externas. A escolha da classificação proposta por Sutton (1988) também foi utilizada, a qual partiu das preferências do autor dessa pesquisa, apesar de haver outros métodos de classificação não menos importantes. É importante salientar que essa metodologia não se configura em um processo pronto e acabado, fechado a qualquer tipo de crítica. Pelo contrário, é uma metodologia em constante processo de evolução e críticas construtivas serão sempre bem-vindas.

Para uma melhor discussão e compreensão dos temas, o artigo está assim dividido: na parte teórica são abordados os temas fontes de informação, informação e tomada de decisão; na parte metodológica são apresentadas as etapas da metodologia e as respectivas escalas de mensuração do nível de dependência (freqüência de uso versus grau de importância da fonte de informação). Para a construção dessa metodologia partiu-se, então, da seguinte premissa: quanto maior for a freqüência de uso e também a importância percebida pelo decisor em relação a uma determinada fonte de informação para a sua tomada de decisão, maior será a dependência do decisor em relação a esta fonte de informação, e vice-versa.

\section{Fontes de informação, informação e tomada de decisão}

Para Choo (2003), a tomada de decisão nas organizações requer informações capazes de reduzir o nível de incerteza. Segundo ele, a informação pode reduzir a incerteza no processo decisório de três maneiras principais: estruturando uma situação de escolha; definindo preferências e selecionando regras; e, por último, fornecendo informações sobre as alternativas viáveis e suas possíveis conseqüências. O QUADRO 1 apresenta a importância da informação na tomada de decisões. 
Proposta de uma metodologia para mensurar o nível de dependência do tomador de decisão em relação às fontes de informações: o caso dos pequenos varejos da região do

Barro Preto em Belo Horizonte

\section{QUADRO 1- Necessidades, busca e uso da informação na tomada de decisões}
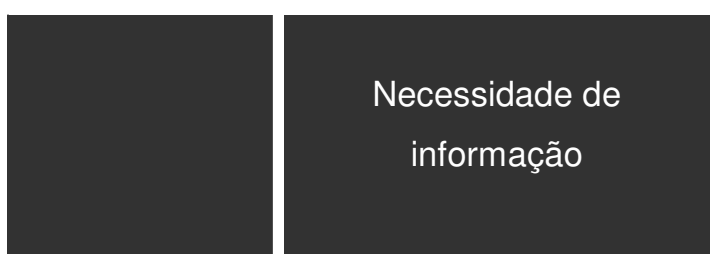

Determinar a estrutura e os limites do problema.

Tomada de

Decisões

Esclarecer preferências e adequação da regra.

Informações sobre

alternativas, resultados, preferências.

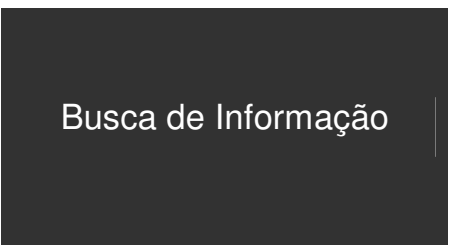

Guiada por princípios heurísticos e hábitos.

Busca motivada por problema.

Critérios para uma solução satisfatória.

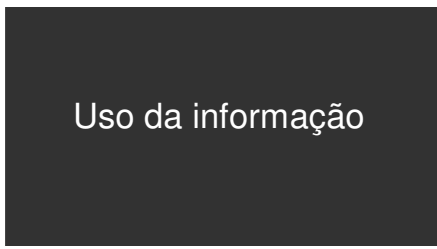

\section{Limitações no} processamento da

informação.

Estruturado por rotinas e regras.

Muitos problemas competem por atenção.

\section{Simplificações e} decisório: inteligência,

Necessidades criação, escolha, revisão. Identificação e

Cognitivas desenvolvimento das necessidades.

\section{Estresse devido à} complexidade, ao risco,

Reações emocionais aos múltiplos interesses e aspirações.

Fatores emocionais na formulação do problema.

Decisões programadas e não programadas.

Dimensões Situacionais

Táticas para elaborar problemas.
Múltiplas regras para gerenciamento das decisões.

Alta velocidade na tomada de decisões.

\section{Modelo conflituoso de} tomada de decisões, aderência ou mudança não conflituosa. Evitação defensiva, hipervigilância, vigilância.

Tipos de processos decisórios: esporádico, fluido e reprimido.

Estrutura, incentivos e acesso à informação.
Pressão para aderir ao pensamento do grupo.

Excesso de compromisso

em situações de crescimento.

Regras para lidar com a informação: regras de percurso e regras de filtragem.

Absorção da incerteza.

Fonte: CHOO (2003, p. 303). 
Choo (2003) ainda adverte que a disponibilidade e a acessibilidade da informação são influenciadas por muitos aspectos institucionais, em especial a estrutura organizacional que regula o fluxo de informação e os sistemas de incentivo que atribuem valor e preferência à consecução de certos objetivos e informações. Para ele, a hierarquia e a especialização são meios tradicionais pelos quais as organizações aumentam a sua capacidade de processar informações com o objetivo de satisfazer os requisitos de desempenho ( $\mathrm{CHOO}, 2003)$.

Existe uma infinidade de classificações e estudos sobre fontes de informações na literatura. Pereira e Barbosa (2008), por exemplo, utilizaram o seguinte esquema de classificação em uma pesquisa realizada com 104 consultores, conforme demonstrado na FIG. 1.

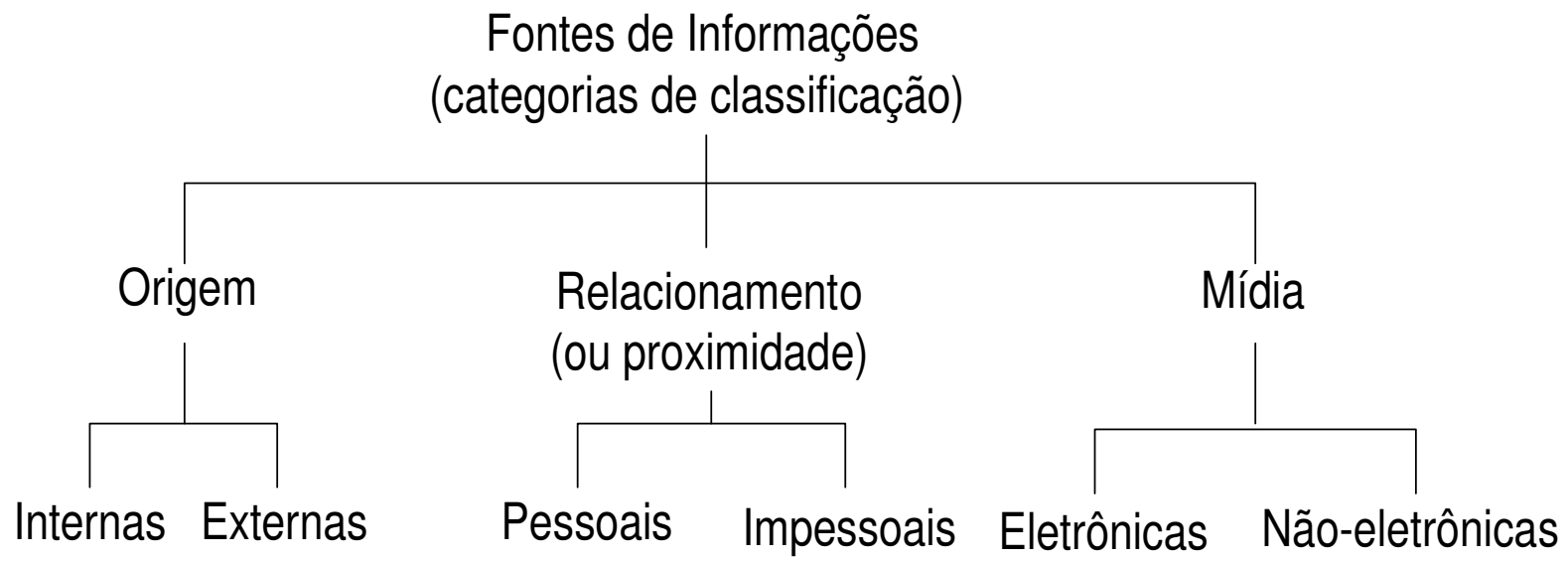

FIGURA 1 - Categorização das Fontes de Informação

FONTE: adaptado de PEREIRA e BARBOSA (2008, p.95).

Pereira e Barbosa (2008) chamam as fontes pessoais de informal ou não estruturadas e as fontes impessoais de formais ou estruturadas, as quais são importantes para a busca de informações relevantes de caráter documental ou formal. Ainda segundo esses autores, são exemplos de mídias eletrônicas a internet, CD-ROMs, disquetes e base de dados online. Por outro lado, as mídias não-eletrônicas são aquelas informações que estão documentadas em papéis, como, por exemplo, os relatórios, documentos, entre outros.

$\mathrm{Na}$ tentativa de categorização das fontes de informação, Daft e Lengel (1986) também classificam as fontes de informação em interna e externa. Segundo eles, algumas fontes de informação externas podem ser os periódicos e jornais da área comercial, amigos na indústria, clientes entre outros. Internamente, as fontes citadas pelos autores foram as reuniões formais e não agendadas e os passeios pela empresa, entre outras. Borges (1995) complementa os estudos desses autores ao apresentar algumas das principais fontes de informações que poderão ser utilizadas pelas organizações, como por exemplo, as suas equipes de vendas e de engenharia, os fornecedores, as agências de publicidade, os 
próprios concorrentes, como também as associações comerciais e as empresas de pesquisas mercadológicas, entre outras.

No que tange ao processo de busca de informação, Wilson (2000) apresenta dois sub-conceitos para explicar o comportamento de busca informacional. O primeiro deles relata que o comportamento de busca por informações é uma conseqüência de satisfazer uma necessidade e/ou objetivo. O segundo conceito se refere ao termo pesquisa informacional, 0 qual representa "o nível micro do comportamento do pesquisador em interações mentais, intelectuais envolvendo julgamentos da relevância do dado ou informação recuperada em diversos tipos de sistemas de informação" (WILSON, 2000, p. 49-50). Assim, pode-se dizer que uma informação é útil ou importante para a organização quando ela tem impacto no alcance dos objetivos e metas organizacionais.

Choo (2003), nesta mesma linha de raciocínio, também reflete sobre a importância da informação para o desempenho organizacional. Para ele, toda informação deve atender a um ou vários objetivos organizacionais, podendo ser agrupados em três campos ou arenas: a primeira delas aborda a necessidade de interpretação da informação para dar significado ao que está acontecendo com a empresa em um determinado ambiente; na segunda o autor ressalta a importância da informação para gerar novos conhecimentos; e, na última, a organização processa e analisa a informação para a orientação de seus processos de tomada de decisão. Essas três arenas são interdependentes e dão sentido ao conceito de visão holística do uso da informação (CHOO, 2003).

Ao se tratar dos temas informação e tomada de decisão, é importante a análise das barreiras que podem ocorrer na comunicação da informação. Starec et al (2005), por exemplo, advertem que essas barreiras não são estáticas e nem fixas, elas são móveis e perpassam todas as áreas, podendo ser encontradas separadas ou de forma simultânea. Dentre as principais barreiras apontadas por esses autores têm-se: a má comunicação derivada da falta de diálogo constante; a cultura organizacional, a qual deve respaldar o fluxo informacional, estimulando e dando acesso à informação; a falta de competência das pessoas; e a dependência tecnológica como barreira à comunicação da informação. Para os autores, o valor da tecnologia da informação depende da informação e do papel desempenhado por ela nas organizações, e a logística da organização deve ser pensada para que a informação possa fluir por todos os setores envolvidos, circulando livremente pela organização para que forneça os insumos necessários para uma tomada de decisão cada vez mais eficaz. Para Davenport (2001, apud STAREC et al, 2005, p. 54), "informação e conhecimento são criações humanas e nunca seremos capazes de administrá-los se não levarmos em consideração que as pessoas desempenham um papel fundamental nesse processo".

Como analisado, percebe-se que a informação é um importante recurso para a organização, especialmente para o processo de tomada de decisão. Para reduzir riscos e incertezas é importante que a organização 
esteja sempre atenta às barreiras que possam interferir no processo de comunicação da informação. Desta forma, estar atento à cultura organizacional, às competências das pessoas, a um melhor processo de comunicação com total suporte das tecnologias da informação e da comunicação, parece ajudar a melhorar o fluxo informacional dentro da organização, proporcionando melhores condições para uma tomada de decisão cada vez mais eficiente e eficaz.

Especificamente para essa pesquisa, a informação de qualidade deve estar disponível para que os decisores atuem com o máximo de eficácia possível em suas atividades de decisão. Assim, escolher as fontes de informações adequadas aos diversos processos administrativos e operacionais pode potencializar o processo de tomada de decisão organizacional na busca por um desempenho superior nos mercados em que as organizações estão inseridas.

Como se pôde perceber, a seleção e o uso apropriado de fontes de informações podem ajudar os executivos a tomarem melhores decisões estratégicas. Manter um processo de monitoramento contínuo do ambiente competitivo, por exemplo, pode ajudar as organizações a evitarem ameaças e surpresas desagradáveis, como também, possibilitar a descoberta e a obtenção de novas oportunidades de negócios, condições essenciais para a sobrevivência e o crescimento organizacional nos mercados em que atuam em tempos de grande hostilidade e turbulência competitiva.

A seguir é apresentada a metodologia para a mensuração do nível de dependência do decisor em relação a uma determinada fonte de informação utilizada por ele em seu processo decisório. Parte-se da premissa de que o nível de dependência é variável e depende da freqüência de uso e da importância percebida pelos decisores em relação à fonte de informação utilizada por ele em seu processo decisório. Assim, quanto mais freqüente o uso e maior a importância de uma fonte de informação para a tomada de decisão, maior será a dependência do decisor em relação a esta fonte para a consecução de suas atividades decisórias, e vice-versa.

\section{Metodologia de mensuração do nível de dependência}

Para a consecução do objetivo principal desse estudo, que foi o de propor uma metodologia capaz de mensurar o nível de dependência do decisor em relação às fontes de informações utilizadas por ele em seu processo decisório, a FIG. 2 foi construída, a qual demonstra as principais etapas da metodologia em questão. 


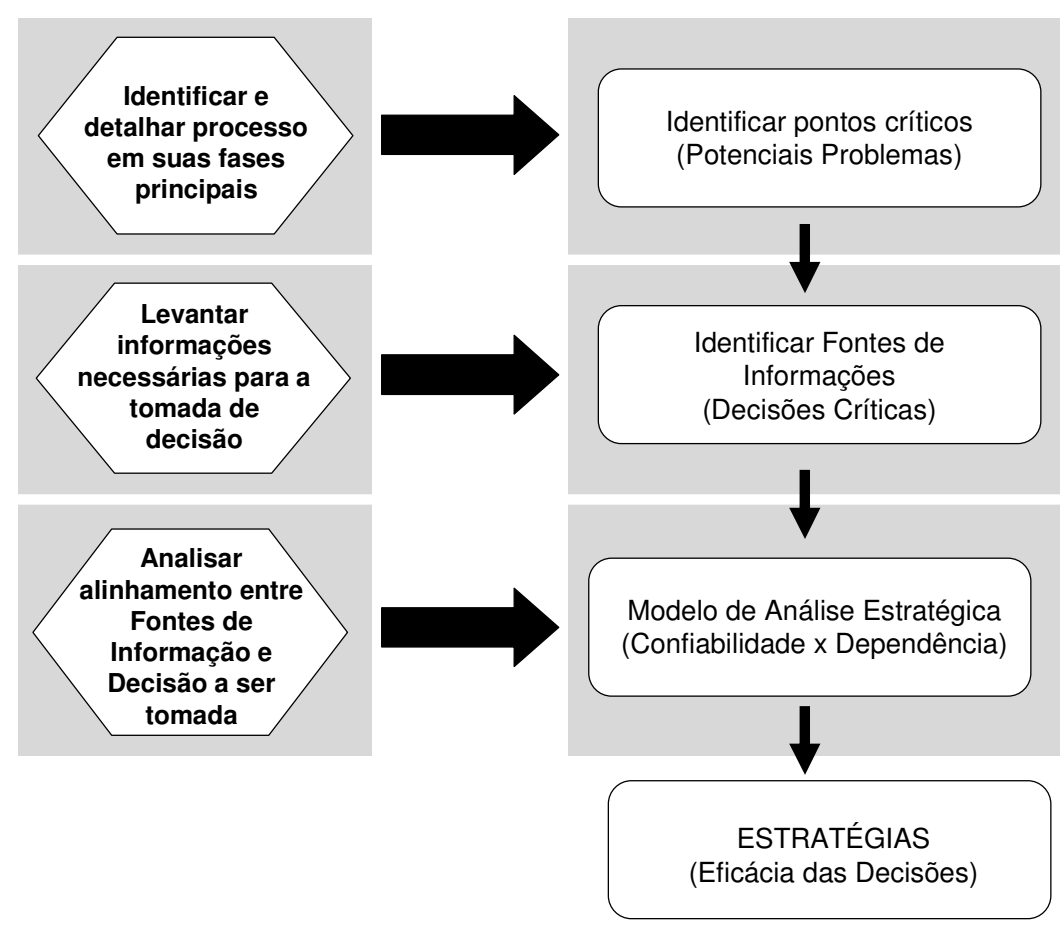

FIGURA 2 - Etapas da metodologia de mensuração do nível de dependência

FONTE: Dados da pesquisa.

A FIG. 2 demonstra sistemicamente os passos a serem seguidos para a mensuração do nível de dependência do decisor em relação às fontes de informações. A primeira fase é composta pelas atividades de identificação e detalhamento do processo organizacional em que as decisões serão tomadas. O objetivo principal desta fase é o de identificar os pontos críticos que possam afetar o funcionamento otimizado do processo de tomada de decisão estratégica. Identificados os pontos críticos, a etapa seguinte analisa as informações necessárias para a tomada de decisão estratégica, caso ocorra algum problema com o processo em questão. Juntamente com o levantamento das necessidades de informação, as potenciais fontes de informações são identificadas e selecionadas com base nos critérios desenvolvidos pelos responsáveis pela coleta de informação. Assim, critérios como acessibilidade e confiabilidade podem ser utilizados nessa etapa. A seleção das fontes de informações vai depender da natureza do problema ou do processo em análise. Nesta etapa podem ser selecionadas fontes internas e/ou externas à organização, conforme demonstrado no QUADRO 2. 
QUADRO 02- Principais fontes de informações à disposição das organizações

\section{Fontes de Informações Internas}

1. Funcionários (de outros departamentos)

2. Funcionários (do próprio departamento)

3. Documentos internos em papel (manuais, normas, regulamentos, etc.).

4. Documentos internos em meio eletrônico (Intranets).

5. Outras

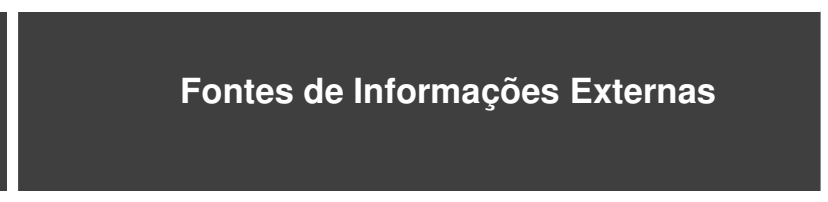

1. Funcionários de outras empresas (concorrentes ou não)

2. Fornecedores da empresa

3. Consumidores

4. Mídia em geral (Rádio, Televisão e Internet)

5. Relatórios publicados por entidades governamentais (BNDS, Ministérios, IBGE, etc).

6. Revistas especializadas (setoriais)

7. Outras

FONTE: adaptado de SUTTON (1988); AUSTER e CHOO (1993); PEREIRA e BARBOSA (2008).

Identificadas as fontes de informações, o próximo passo refere-se à construção de uma metodologia que permita analisar a contribuição de cada fonte de informação para a eficácia do processo decisório. Assim, é analisada a freqüência de uso das fontes de informações por partes dos decisores em uma unidade de tempo (diária, semanal, quinzenal, mensal...) e a sua importância para a tomada de decisão, conforme demonstrado na FIG. 3. É importante destacar que a premissa básica desse modelo é a de que quanto maior for freqüência de uso e a importância dada pelo decisor a uma fonte de informação, maior será a sua dependência em relação a ela para a consecução de suas atividades decisórias, e vice-versa, conforme apresentado anteriormente. Essa conclusão é um tanto quanto óbvia na medida em que ressalta até que ponto o decisor precisa e avalia a necessidade de uma fonte de informação para a consecução de suas atividades decisórias. 


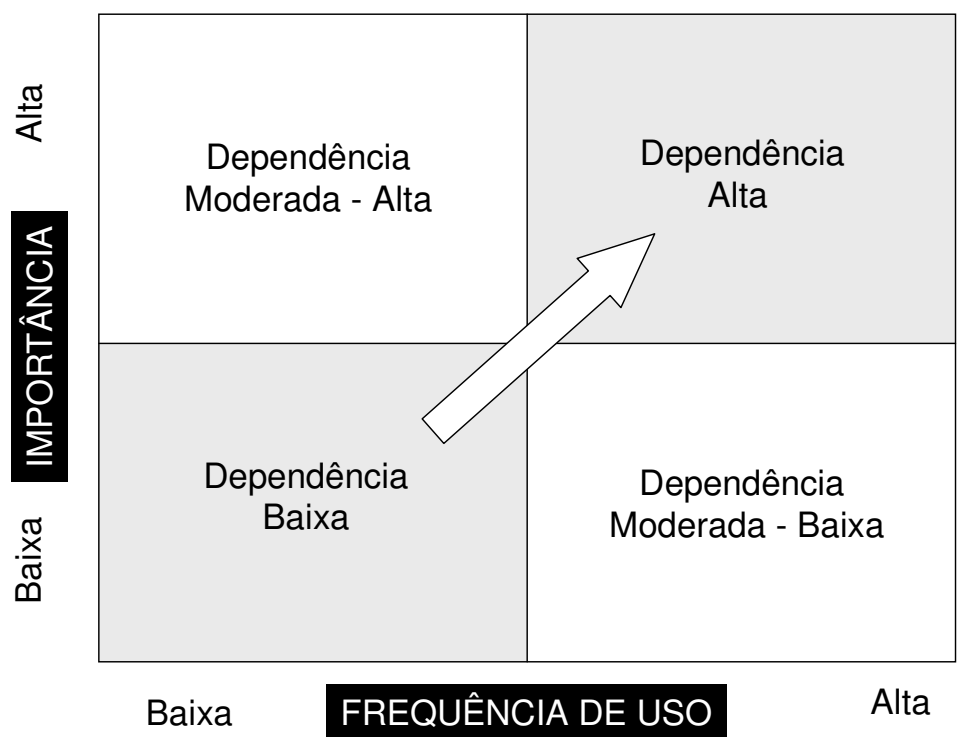

FIGURA 3 - Graus de Dependência com relação ao uso e à importância das fontes de informações

FONTE: autor da pesquisa.

Para medir o grau de dependência dos decisores com relação às fontes de informações utilizadas por eles em seus processos decisórios, as seguintes variáveis foram consideradas: a freqüência de uso das fontes de informações e a importância das mesmas, na percepção dos decisores, para a realização do processo de tomada de decisão. Nesta pesquisa, entende-se por freqüência de uso o número de vezes que uma determinada fonte de informação é utilizada, dentro de um mesmo processo decisório e em uma determinada unidade de tempo, e pode ser diária, semanal, quinzenal, mensal, etc, dependendo da natureza e da complexidade da decisão ou problema. E por importância, entende-se o valor da fonte de informação, percebida pelo decisor, para a consecução de sua tomada de decisão. Assim, pode-se ter fontes de informações imprescindíveis para a realização do processo decisório, como também fontes sem muita importância, onde a sua eliminação (ou não uso) poderá afetar ou não a qualidade e os resultados da decisão tomada. A TAB. 1 apresenta as escalas de mensuração (tipo Likert) do grau de dependência do decisor em relação à fonte de informação. 
TABELA 1 - Escala para mensurar o Grau de Dependência.

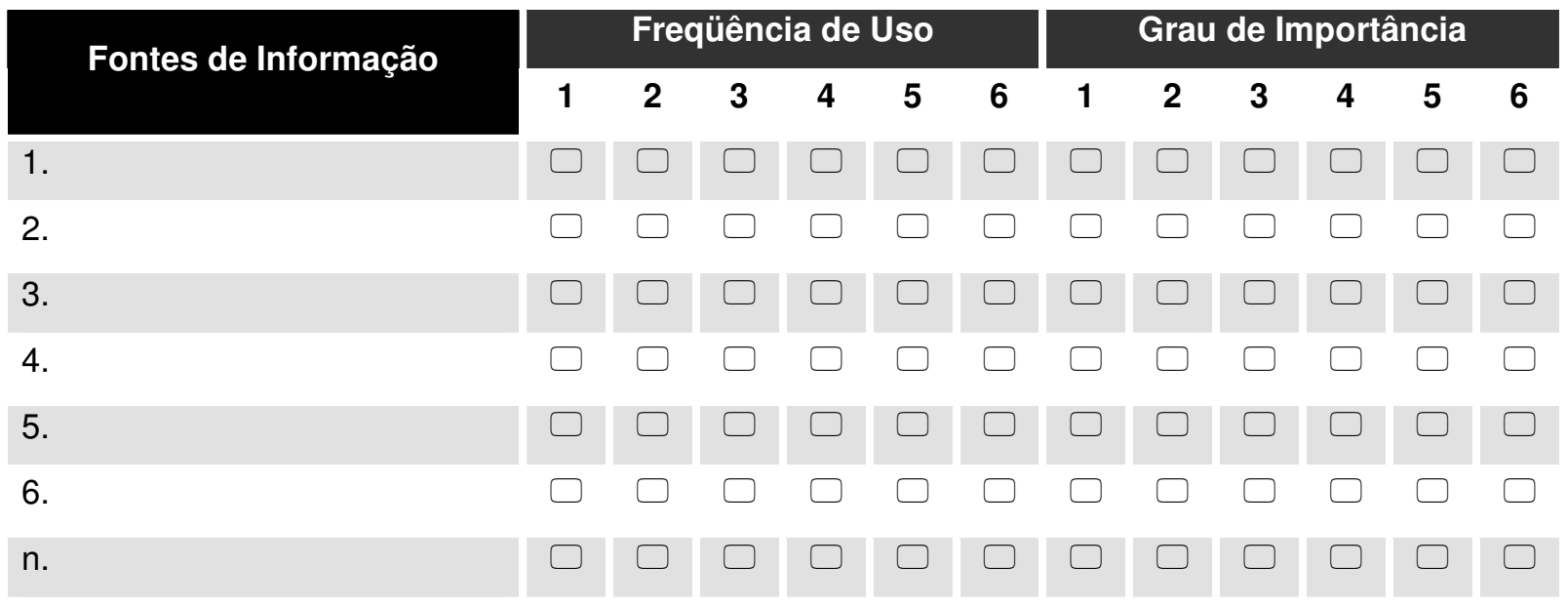

FONTE: Dados da pesquisa.

A mensuração da freqüência de uso das fontes de informações deve ser fundamentada no número de vezes que o tomador de decisão as usa em seu processo decisório por uma unidade de tempo, que pode ser diária, semanal, mensal, bimestral, semestral, ou anual, dependendo de cada processo e de cada organização. A TAB. 2 ilustra a primeira fase de mensuração desta variável.

TABELA 2 - Escala para mensurar a freqüência de uso das fontes de informação

\begin{tabular}{|c|l|}
\hline Valor & Grau \\
\hline 1 & Muito Baixa \\
\hline 2 & Média Baixa \\
\hline 3 & Baixa \\
\hline 4 & Média \\
\hline 5 & Média Alta \\
6 & Muito Alta \\
\hline
\end{tabular}

FONTE: Dados da pesquisa.

Para essa variável, é necessário criar uma tabela auxiliar para quantificar o grau de uso de cada fonte de informação utilizada no processo decisório. Para resolver esse problema, uma segunda tabela é construída para ajudar a mensurar a freqüência de uso.

TABELA 3 - Escala para mensurar a freqüência de uso da fonte de informação no processo decisório

\begin{tabular}{|r|l|}
\hline \multicolumn{1}{|c|}{ Escala } & \multicolumn{1}{|c|}{ Freqüência de uso por unidade de tempo } \\
\hline Muito baixa & De A até B vezes em T (unidade de tempo) \\
\hline Média Baixa & De $\mathrm{B}+1$ a C vezes em T (unidade de tempo) \\
Baixa & De $\mathrm{C}+1$ a D vezes em T (unidade de tempo) \\
\hline Média & De $\mathrm{D}+1$ a E vezes em T (unidade de tempo) \\
\hline Média Alta & De $\mathrm{E}+1$ a F vezes em T (unidade de tempo) \\
\hline Muito Alta & De F + 1 a G vezes em T (unidade de tempo) \\
\hline
\end{tabular}

FONTE: Dados da pesquisa. 


\section{Mensurando o nível de dependência: o caso dos pequenos varejos da região do Barro Preto}

A região do Barro Preto, em Belo Horizonte, é considerada como um dos principais pólos da moda mineira. Situada na região centro-sul, concentra uma grande quantidade de lojas de moda que vendem preferencialmente por atacado. No primeiro semestre de 2008 foram entrevistados nove lojistas da região com o objetivo de identificar seu comportamento informacional em relação à sua tomada de decisão estratégica. Assim, perguntas sobre tipos de fontes de informação, freqüência de uso e importância dessas fontes para a tomada de decisão foram abordadas, conforme demonstrado nas TAB. 4 e 5 . As letras $D, S$, $\mathrm{Q} 1, \mathrm{M}, \mathrm{B}, \mathrm{T}, \mathrm{Q} 2, \mathrm{SE}, \mathrm{A}$ e $\mathrm{E}$ representam a freqüência com que tais lojistas utilizam as fontes de informações para a tomada de decisão. Assim, temse: Diária, Semanal, Quinzenal, Mensal, Bimestral, Quadrimestral, Semestral, Anual e Esporádica, respectivamente.

TABELA 4 - Fontes de Informação e suas Freqüências de Uso na Tomada de Decisão Estratégica

\begin{tabular}{|c|c|c|c|c|c|c|c|c|c|c|c|c|c|c|c|c|c|c|c|c|}
\hline \multirow{2}{*}{ Tipos de Fontes de Informação } & \multicolumn{20}{|c|}{ Frequência de Uso das Fontes de Informação } \\
\hline & D & $\mathrm{Fr}$ & S & $\mathrm{Fr}$ & Q1 & $\mathrm{Fr}$ & M & $\mathrm{Fr}$ & B & $\mathrm{Fr}$ & $\mathrm{T}$ & $\mathrm{Fr}$ & Q2 & $\mathrm{Fr}$ & SE & $\mathrm{Fr}$ & A & $\mathrm{Fr}$ & $\mathrm{E}$ & $\mathrm{Fr}$ \\
\hline Televisão & 1 & $7 \%$ & 0 & $0 \%$ & 0 & $0 \%$ & 1 & $13 \%$ & 0 & $0 \%$ & 0 & $0 \%$ & 0 & $0 \%$ & 0 & $0 \%$ & 0 & $0 \%$ & 1 & $20 \%$ \\
\hline Rádio & 1 & $7 \%$ & 0 & $0 \%$ & 0 & $0 \%$ & 1 & $13 \%$ & 0 & $0 \%$ & 0 & $0 \%$ & 0 & $0 \%$ & 0 & $0 \%$ & 0 & $0 \%$ & 1 & $20 \%$ \\
\hline Jornais Impressos & 2 & $14 \%$ & 0 & $0 \%$ & 0 & $0 \%$ & 1 & $13 \%$ & 0 & $0 \%$ & 0 & $0 \%$ & 0 & $0 \%$ & 1 & $25 \%$ & 0 & $0 \%$ & 0 & $0 \%$ \\
\hline Revistas Especializadas & 0 & $0 \%$ & 2 & $33 \%$ & 0 & $0 \%$ & 1 & $13 \%$ & 0 & $0 \%$ & 1 & $25 \%$ & 0 & $0 \%$ & 1 & $25 \%$ & 0 & $0 \%$ & 0 & $0 \%$ \\
\hline Estudos setoriais (Governo) & 0 & $0 \%$ & 0 & $0 \%$ & 0 & $0 \%$ & 0 & $0 \%$ & 0 & $0 \%$ & 0 & $0 \%$ & 0 & $0 \%$ & 1 & $25 \%$ & 0 & $0 \%$ & 0 & $0 \%$ \\
\hline Participação em Feiras e Eventos & 0 & $0 \%$ & 1 & $17 \%$ & 3 & $75 \%$ & 1 & $13 \%$ & 0 & $0 \%$ & 1 & $25 \%$ & 0 & $0 \%$ & 1 & $25 \%$ & 0 & $0 \%$ & 0 & $0 \%$ \\
\hline Funcionários da Própria Empresa & 2 & $14 \%$ & 1 & $17 \%$ & 0 & $0 \%$ & 0 & $0 \%$ & 0 & $0 \%$ & 1 & $25 \%$ & 0 & $0 \%$ & 0 & $0 \%$ & 0 & $0 \%$ & 0 & $0 \%$ \\
\hline Funcionários de Outras Empresas (não concorrentes) & 1 & $7 \%$ & 1 & $17 \%$ & 0 & $0 \%$ & 0 & $0 \%$ & 0 & $0 \%$ & 0 & $0 \%$ & 0 & $0 \%$ & 0 & $0 \%$ & 0 & $0 \%$ & 0 & $0 \%$ \\
\hline Funcionários dos Concorrentes & 0 & $0 \%$ & 0 & $0 \%$ & 1 & $25 \%$ & 0 & $0 \%$ & 0 & $0 \%$ & 0 & $0 \%$ & 0 & $0 \%$ & 0 & $0 \%$ & 0 & $0 \%$ & 0 & $0 \%$ \\
\hline Especialistas do Ramo & 0 & $0 \%$ & 0 & $0 \%$ & 0 & $0 \%$ & 0 & $0 \%$ & 0 & $0 \%$ & 0 & $0 \%$ & 0 & $0 \%$ & 0 & $0 \%$ & 0 & $0 \%$ & 0 & $0 \%$ \\
\hline Amigos, Parentes, Conhecidos, etc. & 3 & $21 \%$ & 1 & $17 \%$ & 0 & $0 \%$ & 1 & $13 \%$ & 0 & $0 \%$ & 0 & $0 \%$ & 0 & $0 \%$ & 0 & $0 \%$ & 0 & $0 \%$ & 1 & $20 \%$ \\
\hline Clientes & 4 & $29 \%$ & 0 & $0 \%$ & 0 & $0 \%$ & 1 & $13 \%$ & 0 & $0 \%$ & 1 & $25 \%$ & 0 & $0 \%$ & 0 & $0 \%$ & 0 & $0 \%$ & 1 & $20 \%$ \\
\hline Fornecedores & 0 & $0 \%$ & 0 & $0 \%$ & 0 & $0 \%$ & 1 & $13 \%$ & 0 & $0 \%$ & 0 & $0 \%$ & 0 & $0 \%$ & 0 & $0 \%$ & 0 & $0 \%$ & 1 & $20 \%$ \\
\hline TOTAL & 14 & $100 \%$ & 6 & $100 \%$ & 4 & $100 \%$ & 8 & $100 \%$ & 0 & $0 \%$ & 4 & $100 \%$ & 0 & $0 \%$ & 4 & $100 \%$ & 0 & $0 \%$ & 5 & $100 \%$ \\
\hline
\end{tabular}

FONTE: OLIVEIRA et al $(2008$, p.11).

TABELA 5 - Fontes de Informação e a sua Importância para a Tomada de Decisão Estratégica

\begin{tabular}{|c|c|c|c|c|c|c|c|c|c|c|}
\hline \multirow{2}{*}{ Tipos de Fontes de Informação } & \multicolumn{10}{|c|}{ Grau de Importância } \\
\hline & 1 & Fr & 2 & Fr & 3 & Fr & 4 & $\mathbf{F r}$ & 5 & $\mathrm{Fr}$ \\
\hline Televisão & 0 & $0 \%$ & 0 & $0 \%$ & 0 & $0 \%$ & 0 & $0 \%$ & 3 & $33 \%$ \\
\hline Rádio & 0 & $0 \%$ & 0 & $0 \%$ & 0 & $0 \%$ & 0 & $0 \%$ & 3 & $33 \%$ \\
\hline Revistas Especializadas & 0 & $0 \%$ & 0 & $0 \%$ & 2 & $22 \%$ & 1 & $11 \%$ & 2 & $22 \%$ \\
\hline Estudos setoriais (Governo) & 0 & $0 \%$ & 1 & $11 \%$ & 0 & $0 \%$ & 0 & $0 \%$ & 0 & $0 \%$ \\
\hline Funcionários de Outras Empresas (não concorrentes) & 0 & $0 \%$ & 0 & $0 \%$ & 1 & $11 \%$ & 0 & $0 \%$ & 0 & $0 \%$ \\
\hline Funcionários dos Concorrentes & 0 & $0 \%$ & 1 & $11 \%$ & 0 & $0 \%$ & 0 & $0 \%$ & 0 & $0 \%$ \\
\hline Especialistas do Ramo & 0 & $0 \%$ & 0 & $0 \%$ & 0 & $0 \%$ & 0 & $0 \%$ & 0 & $0 \%$ \\
\hline Amigos, Parentes, Conhecidos, etc. & 0 & $0 \%$ & 1 & $11 \%$ & 0 & $0 \%$ & 1 & $11 \%$ & 3 & $33 \%$ \\
\hline Clientes & 0 & $0 \%$ & 0 & $0 \%$ & 3 & $33 \%$ & 3 & $33 \%$ & 5 & $56 \%$ \\
\hline
\end{tabular}

FONTE: OLIVEIRA et al (2008, p.11). 
Compilando-se os dados das Tabelas 4 e 5 , encontram-se os dados da Tabela 6, a qual serviu de base para a construção da FIG. 4, conforme demonstrado a seguir. Nesta parte torna-se necessário realizar alguns ajustes na escala, pois os dados iniciais coletados na pesquisa de Oliveira et al (2008) não permitem fazer a comparação entre as variáveis "Freqüência de Uso" e "Grau de Importância" das fontes de informações utilizadas para a tomada de decisão. Assim, os seguintes critérios foram utilizados no processo de ajuste.

1. Freqüência de Uso: a fonte que apresentar maior freqüência de uso em um determinado período de tempo (diário, semanal, quinzenal, mensal, etc.) ganha a nota 5, sendo escalonado até chegar ao número 1, que representa a menor porcentagem de respostas dadas pelos lojistas à freqüência de uso de uma determinada fonte.

2. Grau de Importância: foi analisado horizontalmente. A ponderação que tiver a maior porcentagem de resposta será a considerada na construção da FIG. 4. Em caso de empate, optar-se-á pela nota do meio.

Assim, o primeiro exemplo é demonstrado pela TAB. 4. As fontes Televisão, Rádio e Funcionários de outras empresas não concorrentes, no período de tempo diário, apresentaram $7 \%$ das respostas, em comparação com os $29 \%$ dados aos clientes, $21 \%$ aos parentes, amigos, entre outros e $14 \%$ aos funcionários da própria empresa e aos jornais. As demais fontes não apresentaram resultados significativos. Assim, considerou-se a ponderação 5 para a maior freqüência (cliente - 29\%), a ponderação 4 para a fonte parentes, amigos, entre outros (21\%), e assim por diante, conforme demonstrado na TAB. 6 . É evidente que em pesquisas futuras essa conversão se tornará desnecessária, uma vez que as tabelas 4 e 5 poderão orientar o processo de coleta de dados ao considerar os respectivos critérios de ajuste. Em síntese, a TAB. 6 reflete os dados convertidos em uma base comum de ponderação, conforme critérios de conversão utilizados para freqüência de uso e grau de importância da fonte de informação para a tomada de decisão estratégica. 
TABELA 6- Nível de Dependência Diária das Fontes de Informação

\begin{tabular}{|l|r|r|r|r|r|}
\hline \multicolumn{2}{l|}{ Fonte de Informação } & NFrU & GD & Dependência \\
\hline F1 & Televisão & 2 & 5 & Moderada-Alta \\
\hline F2 & Rádio & 2 & 5 & Moderada-Alta \\
\hline F3 & Jornais Impressos & 3 & 4 & Alta \\
\hline F4 & Revistas Especializadas & 1 & 4 & Moderada-Alta \\
\hline F5 & Estudos setoriais (Governo) & 1 & 2 & Baixa \\
\hline F6 & Participação em Feiras e Eventos & 1 & 5 & Moderada-Alta \\
\hline F7 & Funcionários da Própria Empresa & 3 & 5 & Alta \\
\hline F8 & Funcionários de Outras Empresas (não & 2 & 3 & Moderada-Alta \\
\hline F9 & Funcionários dos Concorrentes & 1 & 2 & Baixa \\
\hline F10 & Especialistas do Ramo & 1 & 1 & Baixa \\
\hline F11 & Amigos, Parentes, Conhecidos, etc. & 4 & 5 & Alta \\
\hline F12 & Clientes & 5 & 5 & Alta \\
\hline F13 & Fornecedores & 1 & 1 & Baixa \\
\hline
\end{tabular}

FONTE: Tabelas 4 e 5 (NFrU - Nível de Freqüência de Uso; GD - Grau de Dependência)

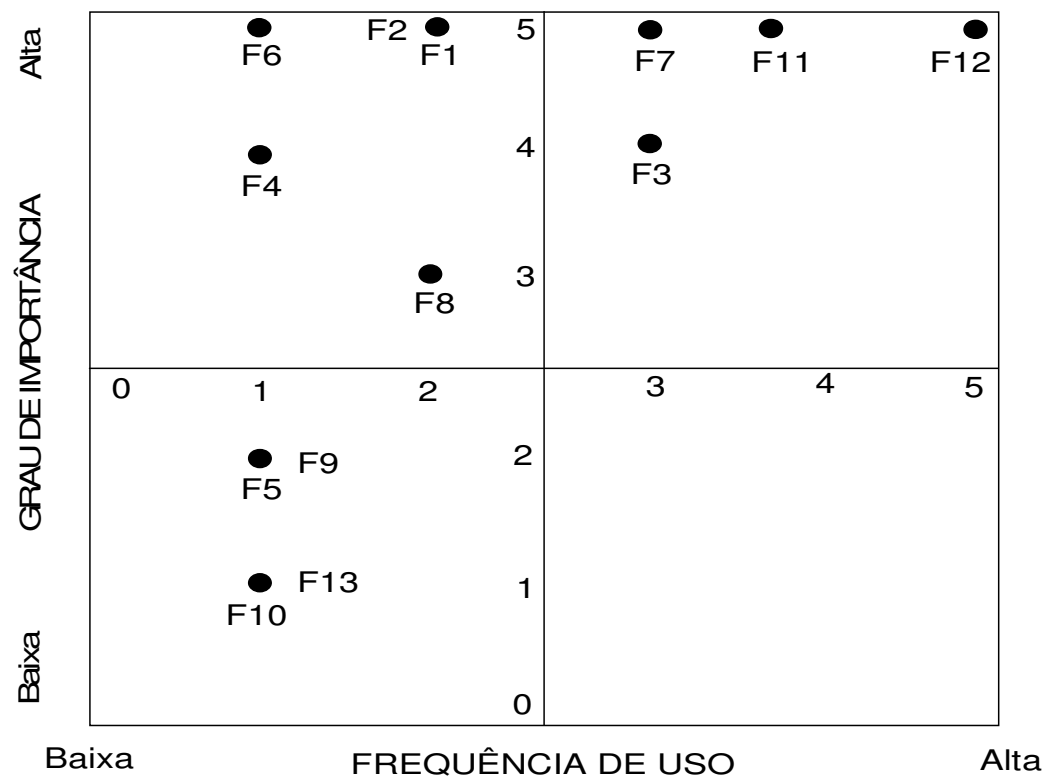

FIGURA 4 - Nível de Dependência do Decisor em relação às Fontes de Informações

FONTE: dados compilados da Tabela 6. 
A FIG. 4 revela, então, os níveis de dependência do decisor em relação às fontes de informação utilizadas por ele em seu processo decisório em uma determinada unidade de tempo, que neste caso é a diária. Assim, perguntou-se a nove lojistas da região do Barro Preto qual seria a freqüência de uso diária e a importância de cada uma das fontes de informações utilizadas por eles na tomada de decisão estratégica. Processando os dados coletados na metodologia proposta chegou-se às seguintes conclusões:

1. Fontes de alta dependência: clientes, amigos, parentes, conhecidos, funcionários da própria empresa e jornais impressos. Assim, percebe-se que, de uma maneira geral, os decisores têm uma grande dependência com relação a essas fontes para as suas tomadas de decisões estratégicas. Neste sentido, aconselha-se a adoção de estruturas administrativas e organizacionais que facilitem e agilizem o processo de coleta de informações de tais fontes.

2. Fontes de moderada-alta dependência: televisão, rádio, revistas especializadas, participação em feiras e eventos, funcionários de empresas não concorrentes. Apesar de não terem uma alta freqüência de uso, essas fontes são muito importantes para a tomada de decisão. Assim, conclui-se que essas fontes também precisam ser acompanhadas e gerenciadas de perto, apesar da sua baixa freqüência de uso. Esse fato pode ser explicado pela natureza do problema, que pode envolver decisões de longo prazo e/ou esporádicas.

3. Fontes de moderada-baixa dependência: não foram identificadas fontes de informações com esse perfil no caso em questão.

4. Fontes de baixa dependência: estudos setoriais do governo, funcionários dos concorrentes, especialistas do ramo e fornecedores. Neste caso, conforme percepção dos decisores, essas fontes não apresentaram relevância significativa para a tomada de decisão estratégica. Assim, aconselha-se a redução das estruturas administrativas e organizacionais disponibilizadas para a gestão e o controle de tais fontes de informação, o que não significa a sua exclusão do controle gerencial. É importante destacar que outros dados precisam ser coletados para verificar com maior profundidade o porquê de tais fontes não apresentaram dependência significativa, uma vez que elas são bastante referenciadas em estudos sobre monitoramento ambiental e inteligência competitiva.

\section{Considerações finais e recomendações}

A informação é o insumo básico para qualquer tipo de tomada de decisão. Informações precisas, rápidas e confiáveis parecem ser uma das 
maiores necessidades e preocupações dos executivos nesse novo contexto competitivo, o qual tem sido determinado pela grande complexidade e dinamicidade dos seus elementos constituintes (D'AVENI, 1995; HITT et al, 2003). Hoje, vive-se em uma era de incertezas, onde a sobrevivência e o crescimento das organizações dependem, dentre outras coisas, das suas capacidades de obter, armazenar, processar e recuperar informações úteis para a tomada de decisão que facilite o ajuste contínuo e eficaz das organizações às mudanças ambientais (OLIVEIRA et al, 2008).

Reflexos de uma economia cada vez mais globalizada e dos avanços tecnológicos, a incerteza, a turbulência, a volatilidade e a hostilidade ambientais têm delineado contextos de decisão cada vez mais arriscados para os decisores organizacionais, onde as probabilidades de falhas e insucessos têm aumentado consideravelmente. Assim, criam-se necessidades de buscas constantes por fontes de informações que forneçam os recursos necessários para um processo decisório cada vez mais eficaz. Desta maneira, surge o desafio de se encontrar as fontes que realmente tem relevância para a tomada de decisão.

Mas como medir a relevância de uma fonte de informação para a tomada de decisão? A resposta a esta questão foi a razão principal que justificou a criação da metodologia até então desenvolvida e analisada. Por ser uma metodologia que considera a freqüência de uso de uma fonte de informação e a sua importância para a realização da tomada de decisão, acredita-se que ela poderá potencializar e aumentar a eficácia da tomada de decisão na medida em que ajuda o decisor a identificar e mensurar o seu nível de dependência com relação a uma determinada fonte de informação ao longo do tempo.

No caso específico dos gestores do Barro Preto, verificou-se que as fontes pessoais apresentaram maiores índices de dependência. Esse fato pode ser justificado pela grande proximidade dos decisores em relação a essas fontes (PEREIRA; BARBOSA, 2008) e pela dinamicidade do setor varejista, demandando uma freqüência grande de coleta de informações sobre os fatos, tendências e relacionamentos que acontecem em seus ambientes de negócios. Por outro lado, fontes como especialistas do setor (consultores), fornecedores e funcionários de outras lojas nãoconcorrentes apresentaram uma baixa dependência do decisor. Esse resultado se demonstrou até certo ponto inconsistente, principalmente por que essas fontes têm sido frequentemente referenciadas em pesquisas sobre monitoramento ambiental e inteligência competitiva. Assim, sugerese a realização de pesquisas mais aprofundadas sobre essa questão.

Como toda metodologia e/ou modelo é passível de atualizações, críticas construtivas serão sempre bem-vindas e consideradas para futuros aperfeiçoamentos dessa metodologia de mensuração do nível de dependência do decisor em relação à fonte de informação utilizada por ele em seu processo decisório, uma vez que esta metodologia se encontra em sua fase inicial, a qual gera mais indagações do que respostas prontas e acabadas. Assim, espera-se que novas pesquisas e contribuições possam 
ser dadas na tentativa de reduzir e/ou eliminar os pontos fracos da referida metodologia.

Finalmente, algumas limitações devem ser apresentadas nesse momento. Primeiro, a metodologia não aborda os fatores pessoais (experiências, habilidades, competências, entre outros) dos decisores, que possam afetar a freqüência de uso e a importância percebida por eles em relação às fontes de informações. Segundo, a metodologia não analisa o impacto da dinâmica do ambiente sobre o comportamento informacional do decisor, e, por último, variáveis como cultura e estrutura organizacional devem ser mais bem explicitadas, principalmente nas fases de identificação, seleção e escolha das fontes de informações, como também das tecnologias da informação e comunicação a serem utilizadas.

\section{Referências}

AGUILAR, F. J. Scanning the business environment. New York: The Macmillan Company, 1967

AUSTER, E.; CHOO, C. W. Environmental scanning by CEOs in two Canadian industries. Journal of the American Society for Information Science, v. 44, n. 4, p. 194-203, 1993.

BORGES, M. E. N. A informação como recurso gerencial das organizações na sociedade do conhecimento. Ciência da Informação, v.24, n.2, 1995.

DAFT, R.; LENGEL, R. Organizational information requirements, media richness and structural design. Management Science, v. 32, n. 4, p. 554571, May 1986.

D'AVENI, R. Hipercompetição. Rio de Janeiro: Campus, 1995.

DAVENPORT, T. H. Ecologia da informação. In: STAREC, C.; GOMES, E. B. P.; BEZERRA, J. (Orgs). Gestão estratégica da informação e inteligência competitiva. São Paulo: Saraiva, 2005.

CHOO, C. W. A organização do conhecimento: como as organizações usam a informação para criar significado, construir conhecimento e tomar decisões. São Paulo: Senac, 2003.

DRUCKER, P. F. The information executives truly need. Harvard Business Review, Jan./Feb. 1995.

HITT, M. A.; IRELAND, R. D.; HOSKISSON, R. E. Administração Estratégica. São Paulo: Bookman, 2003.

MINTZBERG, H. Criando organizações eficazes. 2. ed. São Paulo: Atlas, 2003.

OLIVEIRA, P. H. et al. Contexto competitivo, monitoramento ambiental e tomada de decisão estratégica: o caso dos micro e pequenos varejos da região do Barro Preto em Belo Horizonte. In: FORUM GESTÃO FEAD, 2., Belo Horizonte, 2008, Belo Horizonte. Anais..., 2008. v.2. 
PEREIRA, F. C. M.; BARBOSA, R. R. Uso de fontes de informação por consultores empresariais: um estudo junto ao mercado de consultoria de Belo Horizonte. Perspectivas em Ciências da Informação, v.13, n.1, p.95111, jan./abr., 2008.

SIMON, H. A. Comportamento administrativo: estudo dos processos decisórios nas organizações administrativas. 2.ed. Rio de Janeiro: Fundação Getúlio Vargas, 1965.

STAREC, C; GOMES, E. B. P; BEZERRA, J. (Orgs). Gestão estratégica da informação e inteligência competitiva. São Paulo: Saraiva, 2005.

SUTTON, H. Competitive intelligence (Conference Board Research Report n. 913). New York: The Conference Board, 1988.

WILSON, T. D. Human Information Behavior. In PEREIRA, F. C. M; BARBOSA, R. R. Uso de fontes de informação por consultores empresariais: um estudo junto ao mercado de consultoria de Belo Horizonte. Perspectivas em Ciências da Informação, v.13, n.1, p.95-111, jan./abr., 2008. 